\title{
Feeding kinematics and performance of basal otariid pinnipeds, Steller sea lions and northern fur seals: implications for the evolution of mammalian feeding
}

\author{
Christopher D. Marshall ${ }^{1,2, *}$, David A. S. Rosen ${ }^{3}$ and Andrew W. Trites ${ }^{3}$
}

\begin{abstract}
Feeding performance studies can address questions relevant to feeding ecology and evolution. Our current understanding of feeding mechanisms for aquatic mammals is poor. Therefore, we characterized the feeding kinematics and performance of five Steller sea lions (Eumetopias jubatus) and six northern fur seals (Callorhinus ursinus). We tested the hypotheses that both species use suction as their primary feeding mode, and that rapid jaw opening was related to suction generation. Steller sea lions used suction as their primary feeding mode, but also used a biting feeding mode. In contrast, northern fur seals only used a biting feeding mode. Kinematic profiles of Steller sea lions were all indicative of suction feeding (i.e. a small gape, small gape angle, large depression of the hyolingual apparatus and lip pursing). However, jaw opening as measured by gape angle opening velocity (GAOV) was relatively slow in Steller sea lions. In contrast to Steller sea lions, the GAOV of northern fur seals was extremely fast, but their kinematic profiles indicated a biting feeding mode (i.e. northern fur seals exhibited a greater gape, a greater gape angle and minimal depression of the hyolingual apparatus compared with Steller sea lions). Steller sea lions produced both subambient and suprambient pressures at $45 \mathrm{kPa}$. In contrast, northern fur seals produced no detectable pressure measurements. Steller sea lions have a broader feeding repertoire than northern fur seals, which likely enables them to feed on a greater variety of prey, in more diverse habitats. Based on the basal phylogenetic position of northern fur seals, craniodental morphological data of the Callorhinus lineage, and the performance data provided in this study, we suggest that northern fur seals may be exhibiting their ancestral feeding mode.
\end{abstract}

KEY WORDS: Otariidae, Callorhinus ursinus, Eumetopias jubatus, Suction, Biting, Fossil pinnipeds

\section{INTRODUCTION}

Pinnipeds (seals, sea lions, fur seals and walruses) are a monophyletic lineage of carnivores that have successfully transitioned back to the aquatic environment likely using several independent adaptations for aquatic feeding. Undoubtedly, the modification of the feeding apparatus and prey capture during this transition played a significant part in this clade's success. Extant pinnipeds are thought to exhibit four general feeding modes:

\footnotetext{
${ }^{1}$ Texas A\&M University, Department of Marine Biology, Galveston, TX 77553, USA ${ }^{2}$ Texas A\&M University, Department of Wildlife and Fisheries Sciences, College Station, TX 77840, USA. 'Marine Mammal Research Unit, Institute for the Oceans and Fisheries, University of British Columbia, Vancouver, BC, Canada V6T 1 Z4.

*Author for correspondence (marshalc@tamug.edu)
}

Received 9 June 2015; Accepted 18 August 2015 pierce or raptorial biting (hereafter referred to as biting), grip-andtear, inertial suction (hereafter referred to as suction) and filter feeding (Adam and Berta, 2002). Among otariids, biting, gripand-tear and suction feeding modes are thought to be the most common. Only one otariid (Antarctic fur seals, Arctocephalus gazella) is known to use filter feeding (Riedman, 1990; Adam and Berta, 2002). Biting is considered to be the ancestral feeding condition of basal aquatic vertebrates, as well as the terrestrial ancestors of pinnipeds (Adam and Berta, 2002; Berta et al., 2006). Morphological evidence from Puijila, while not considered a direct ancestor to pinnipeds (Kelley and Pyenson, 2015), suggests that the ancestral biting mode was still in use as mammals transitioned from terrestrial to coastal habitats (Rybczynski et al., 2009). However, recent behavioral and performance data suggest that suction may be the dominant feeding mode among pinnipeds (Marshall et al., 2008, 2014a), or one of several equally important feeding modes (Hocking et al., 2013, 2014; Marshall et al., 2014a). Thus, much remains to be resolved about how aquatic feeding modes among pinnipeds evolved from their ancestral state.

Current knowledge of pinniped feeding mechanisms remains descriptive (with a few exceptions), and lacks the detailed functional analyses found for basal aquatic vertebrates (e.g. actinopterygian fishes). Such detailed quantitative and comparative work has not been conducted for otariid pinnipeds. This is surprising given the selection pressure for diversification of aquatic feeding mechanisms among marine tetrapods is potentially large as a result of theorized physical drivers of ocean circulation change and the subsequent eutrophication and increase in productivity and prey (Mitchell, 1975; Lipps and Mitchell, 1976; Werth, 2000a; Pyenson, et al., 2014). Although minimal, the otariid fossil record suggests a diversity of adaptive phenotypes that could principally result from different feeding mechanisms (e.g. Mitchell, 1975; Demére and Berta, 2005; Berta et al., 2006; Boessenecker, 2011).

A poor understanding of pinniped evolutionary relationships has hampered our understanding of the diversity of adaptations and macroevolutionary patterns for aquatic feeding in this major carnivoran lineage. Recent advances in otariid taxonomy (Wynen et al., 2001; Arnason et al., 2006; Higdon et al., 2007; Dasmahapatra et al., 2009; Wolf et al., 2007; Yonezawa et al., 2009; Berta and Churchill, 2012) have clarified evolutionary relationships among sea lions and fur seals, at least for the most basal clades. Although otariid evolutionary relationships overall still lack consensus, northern fur seals [Callorhinus ursinus (Linnaeus 1758)] are consistently positioned as the most basal living otariid, and Steller sea lions (Eumetopias jubatus Schreber 1776) are also consistently placed in a basal position (Fig. 1). Recent combined evidence analyses (Churchill et al., 2014) 
continue to recover Callorhinus as the earliest extant otariid followed by Neophoca cinerea and Eumetopias (and other members of a northern sea lion clade including Zalophus and Proterozetes) as the next diverging clades.

As phylogenetic frameworks improve, understanding formfunction relationships among extant species will allow for functional inferences to be made for fossil forms (e.g. pinnipedimorphs) and to test hypotheses of macroevolutionary patterns within pinnipeds. Such functional work is critical since analyses using morphology alone are insufficient to make functional assignments regarding feeding mode. For example, leopard seals have been characterized as a typical grip-and-tear predator, but have been recently shown to also use suction feeding and possibly filter feeding modes (Hocking et al., 2013). Inferring the feeding biomechanics of extant species to extinct pinnipeds and their ancestors will require comparative quantitative functional morphological and performance measures that investigate patterns of constraint and functional tradeoffs. Such long-term work is available for some marine tetrapod groups (e.g. locomotion; Kelley and Pyenson, 2015), but is lacking for pinnipeds (Wainwright et al., 2015).

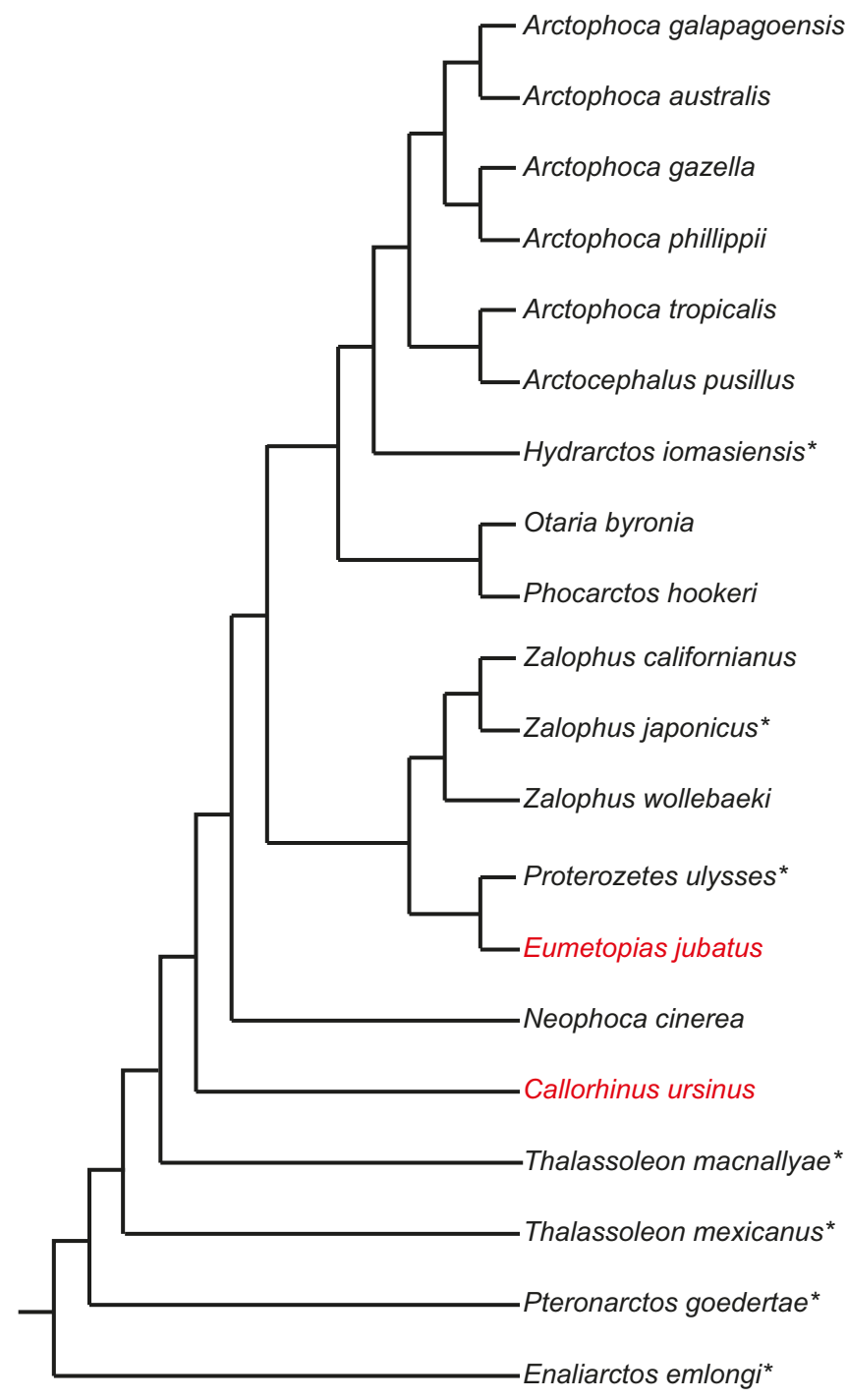

Fig. 1. Phylogeny of extant and extinct otariids. After Churchill et al. (2014) Species included in this study are in red. Asterisks indicate extinct species. One of several possible trees.
Understanding prey-capture tactics and feeding performance is also important when considering trophic ecological questions because they can determine prey choice relative to the energetic constraints of capturing prey (Emlen, 1966; Schoener, 1971; Bowen et al., 2002; Wainwright and Bellwood, 2002). Feeding performance determines the behavioral capacity of an animal to exploit its resources, and has a direct bearing on its fitness (Arnold, 1983; Wainwright and Reilly, 1994). Morphology constrains performance, which in turn constrains the ecology of a species. To date, there are no comparative quantitative functional feeding kinematics and performance data in otariid pinnipeds. Therefore, the objectives of our study were to (1) conduct a kinematic and performance study of two basal otariids (northern fur seals and Steller sea lions) to test the hypothesis that both species use suction as their primary feeding mode, (2) test the hypothesis that suction and biting kinematics of otariids is similar to that of other marine mammals for which data are available, and (3) determine whether rapid jaw opening is correlated with the generation of subambient pressure.

\section{MATERIALS AND METHODS \\ Subjects}

This study was conducted at the Vancouver Aquarium (Vancouver, BC, Canada) and the University of British Columbia (UBC) Open Water Facility (Port Moody, Vancouver, BC, Canada). Six juvenile female northern fur seals $(C$. ursinus) and five adult female Steller sea lions (E. jubatus) participated in this study; all animals were well trained through positive reinforcement and were eager to participate in these novel tasks. All work was approved by UBC's Animal Care Committee and Texas A\&M University's Institute of Animal Care and Use Committee Animal Use Protocol no. 2010-67.

\section{Feeding platform}

A feeding apparatus was constructed from aluminium framing, acrylic and a mirror to present subjects with food items (cut herring and capelin) in a controlled and repeatable research design following Marshall et al. (2008, $2014 \mathrm{a}$ ), with some modifications. Thirty holes, $3.3 \mathrm{~cm}$ in diameter, were drilled through a $70 \times 70 \mathrm{~cm}$ sheet of 2 -cm-thick acrylic in 6 rows and 5 columns, $4 \mathrm{~cm}$ apart. Acrylic cylinders were fixed behind six of the feeding holes to create recessed wells in which food could be placed.

The acrylic feeding surface was attached to an aluminium frame. This frame was then hinged to a second aluminium frame of equal size, which held a mirror fixed at a $30 \mathrm{deg}$ angle to the acrylic feeding surface. An underwater video camera was positioned so that its view was parallel to the feeding surface of the apparatus (Fig. 2) and recorded the lateral perspective of feeding otariids. Pieces of fish were presented to the subjects in two ways, simultaneously. Cut fish were pushed through the holes in the acrylic feeding surface such that portions of fish $(1-2 \mathrm{~cm})$ projected out from the surface, and were accessible to the subjects. In addition, fish were cut to fit within the recessed acrylic cylinders (inner diameter $3.8 \mathrm{~cm}$, length $5.7 \mathrm{~cm}$ ) that were positioned behind six of the feeding holes. Holes $(1 \mathrm{~cm}$ diameter $)$ were drilled through the back of each acrylic cylinder to allow water to flow through. The feeding apparatus was placed in the water, suspended just below the surface, in the vertical plane (Fig. 2). In addition, feeding trials were also conducted with the feeding apparatus out of the water. Subjects hauled out of the water and were allowed to feed from the apparatus in the same manner as during the in-water trials.

Since food was presented to subjects projecting from holes in the feeding surface and from within recessed cylinders during feeding trials, individuals were forced to make several choices to ingest food. When approaching the feeding apparatus full of food, their first choice was whether to consume fish projecting from the holes or fish residing within the recessed cylinder. If a subject chose to consume fish projecting from holes in the feeding apparatus, then it had to choose whether to consume the piece of fish by biting and removing it with their teeth, or to use suction. If a subject chose to consume a piece of fish in the recessed cylinder, then its only option was to use suction to obtain that food item. This allowed us to determine whether subjects used 


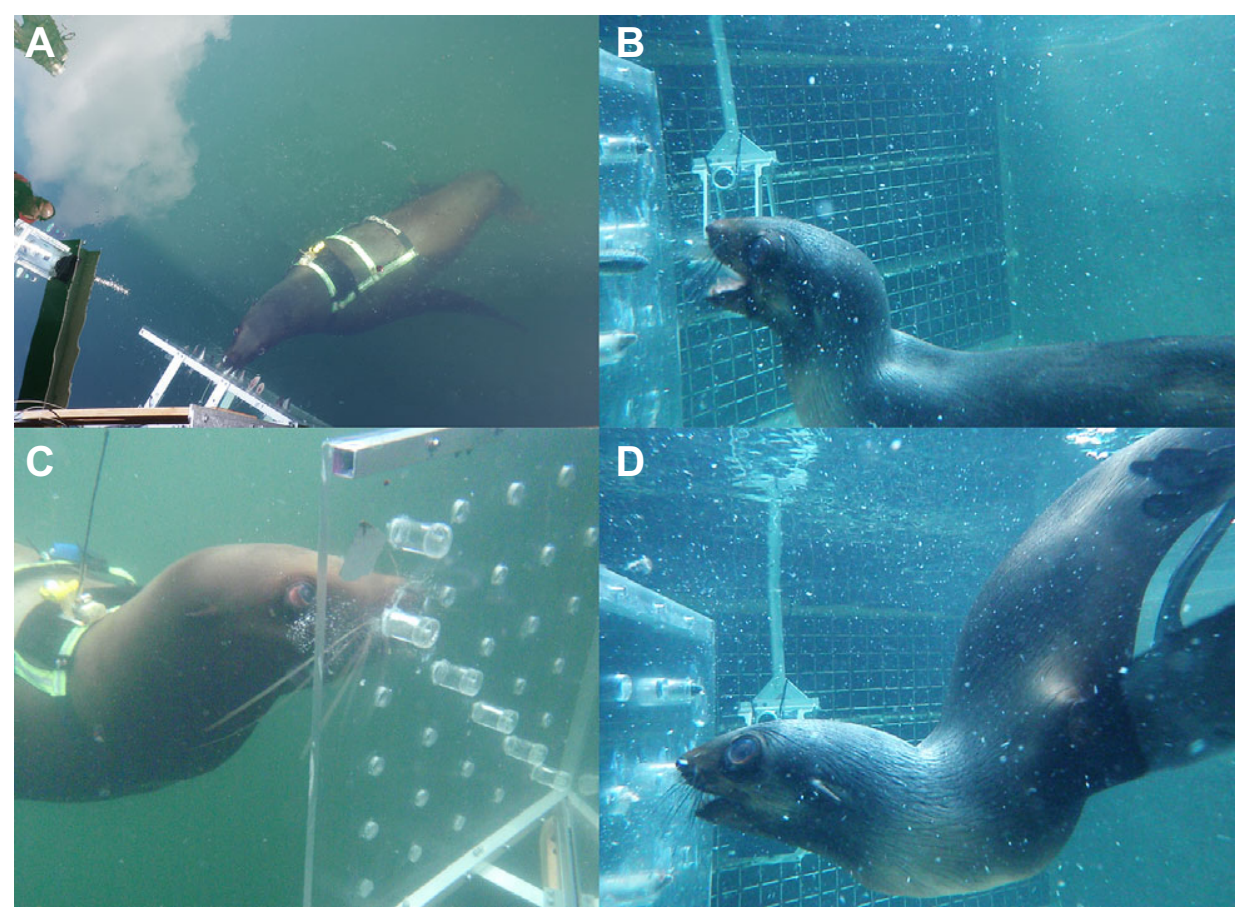

Fig. 2. Subjects feeding from the experimental apparatus. (A) Top-down view of a Steller sea lion feeding from the apparatus. (B) A northern fur seal displaying wide gape with no lateral gape occlusion. (C) A Steller sea lion using suction and vibrissae. (D) A northern fur seal using vibrissae while using a biting feeding mode. biting or suction as their primary feeding mode. To challenge subjects and elicit maximum suction and hydraulic jetting performance measures, the cylinder where pressure measurements were collected was partially occluded $(\sim 1 \mathrm{~cm})$ such that food items could not simply slide out of the tube, but instead had to be 'lifted' over a ridge between the cylinder and the location where seals placed their muzzle before it became available. To extract fish, enough pressure had to be employed to pull the food item up and over this ridge. In addition, numerous pieces of fish were packed into each cylinder in an effort to make extraction difficult and elicit powerful suction forces.

The alternating use of suction with hydraulic jetting was successful because movement of the food items increased the chance that the food item could be lifted over the ridge. The use of suction and hydraulic jetting was confirmed by the appearance of bubbles from turbulence flowing from the back of the recessed cylinders toward the subject's lips during suction events, alternating with cloudy plumes of minute fish particles and scales exiting the back of the recessed wells during hydraulic jetting events, in addition to direct pressure measurements (see below). Both kinematic and pressure data were used to categorize each feeding event as suction or biting. A hermetically sealed pressure catheter was placed through one of the cylinders to directly measure suction forces simultaneously with kinematic events (see below).

\section{Feeding events, kinematic variables and analyses}

A total of 209 feeding events from four Steller sea lions ( $N=105$ feeding events) and from six northern fur seals ( $N=104$ feeding events) were conducted for the kinematic analyses. Of these feeding events, 181 met our kinematic criteria for data analysis inclusion. These feeding events were approximately split between in-water events $(N=97)$ and on-land events $(N=83)$. More specifically, Steller sea lion feeding trials were composed of 48 in-water events, and 35 on-land events. Similarly, northern fur seal feeding trials were composed of 49 in-water events and 48 on-land events.

To meet our kinematic criteria, the cranial landmarks of each subject and the food items had to be visible within each video frame during an entire feeding event, and rotation of the body around the longitudinal axis had to be minimal $(<5 \mathrm{deg})$. This necessitated conducting many more feeding trials than were ultimately used in the kinematic analyses, but these trials provided important behavioral and pressure data.

Subjects were video recorded at $60 \mathrm{~Hz}$ using a Sony camcorder within an underwater video housing. To assist in digitizing footage for motion analysis, prior to feeding trials, zinc oxide landmarks were placed on the subject's lips, jaws and hyoid apparatus. These homologous, high-contrast landmarks were digitized frame-by-frame using Motus 9.0 motion analysis software system (Vicon, Denver, CO, USA). Digitized points were placed within spatial models and used to calculate kinematic variables.

Kinematic variables measured included: (1) maximum gape, the maximum distance from the maxillary tip to the mandibular tip; (2) time to maximum gape, the time from when the lower jaw began to open until maximum gape; (3) maximum gape angle, the maximum angle from the maxillary tip to the corner of the mouth to the mandibular tip; (4) time to maximum gape angle, the time from when the lower jaw began to open until maximum gape angle; (5) maximum gape angle opening velocity (GAOV), the greatest angular rate of lower jaw opening; (6) time to maximum GAOV, the time from when the lower jaw began to open until maximum GAOV was achieved; (7) maximum gape angle closing velocity (GACV), the greatest angular velocity during lower jaw closure; (8) time to maximum GACV, the time from when the lower jaw began to close until maximum gape angle velocity was achieved; (9) maximum gular depression, the greatest increase in distance from the eye to the external rostral border of the hyoid; and (10) time to maximum gular depression, the time from the start of gular depression to maximum gular depression. Total feeding cycle duration was also calculated. These kinematic variables were selected to determine the behavioral repertoire of prey capture, and characterize the feeding mode of Steller sea lions and northern fur seals. They were also selected to test the hypothesis that rapid jaw opening (GAOV) contributes to subambient pressure generation, and build upon our comparative feeding performance dataset for marine mammals (following Bloodworth and Marshall, 2005; Marshall et al., 2008, 2014a; Kane and Marshall, 2009).

To compare maximum gape and gape angle possible (maximum biological gape and gape angle) with the maximum gape and gape angle used during feeding events (maximum kinematic gape and gape angle), each subject was digitally photographed while opening their mouth to their widest extent at the command of a trainer. Maximal biological gape and gape angle were measured from scaled digital photographs using ImageJ (National Institutes of Health, Bethesda, MD, USA). Maximum kinematic gape and gape angle during feeding events were compared with the mean maximum biological gape and gape angle for all animals in the study.

\section{Pressure measurements}

A total of 323 pressure trials resulted in 238 measurements from all Steller sea lions, and a total of 223 pressure trials resulted in zero pressure measurements that met our criteria from all northern fur seal subjects. Pressure measurements were recorded simultaneously with kinematic 
events. Many more pressure measurements were collected than kinematic feeding events since our criteria for acceptance of pressure measurements for analyses were not as restrictive. Pressure measurements were collected using a Millar MPC-500 catheter pressure transducer connected to a transducer control box (Millar TCB-600, Houston, TX, USA) and a Biopac MP150 portable electrophysiological recording system (Biopac, Oleta, CA, USA). Pressure data were saved to a laptop using Acqknowledge software (Biopac).

Pressure data were synchronized with video footage (for behavioral and kinematic data analysis) using an electronic device that generated a square wave pattern and a corresponding flashing pattern of dual LED lights. The LED display was affixed to the feeding platform and recorded by the camcorder. The square wave pattern was recorded as a second channel simultaneously with pressure data collection in Acqknowledge. This allowed synchronization of the suction feeding behavior with pressure measurements in Acqknowledge.

The pressure transducer was calibrated using the Millar control box, but also in the laboratory under a range of known pressure regimes. Prior to each feeding trial, a pressure transducer was placed through the back of a recessed cylinder (that contained food) so that the tip of the transducer, where the recording element was located, projected $\sim 1 \mathrm{~cm}$ beyond the acrylic feeding surface. This allowed the pressure sensor to be just at the subject's lips, or slightly within the oral cavity, during feeding. This distance was verified visually during the feeding trials and from video footage.

Our criteria for analyzing pressure data were that both the subject and the LED lights had to be within the video frame, the tip of the transducer should project $\sim 1 \mathrm{~cm}$ beyond the acrylic feeding surface and pressure measurements must exceed $\pm 0.1 \mathrm{~V}(\sim 5 \mathrm{kPa})$ in magnitude to be included in the data analysis. The maximum amplitude and duration of every subambient and suprambient pressure event were measured. Prior work on bearded seal pressure generation (Marshall et al., 2008) demonstrated that suction generated when feeding from the apparatus did not differ from suction values collected during hand feeding.

\section{Statistics}

All data were tested for normality and variance equivalence. A full factorial two-way ANOVA was performed to determine significant differences $(\alpha \leq 0.05)$ of kinematic data during feeding trials for the categorical treatment of all kinematic variables behavior versus species and location and species $\times$ location interaction followed by Tukey's post hoc tests. A full factorial two-way analysis of species versus feeding mode was not possible because northern fur seals only exhibited one feeding mode. Therefore, additional one-way ANOVA investigated the kinematic profile of suction versus biting feeding modes in Steller sea lions, and the biting feeding mode of northern fur seals in water versus on land. Each one-way ANOVA was followed by Student's $t$-test to compare groups for significance. A principal components (PC) analysis on correlations was performed on the kinematic data as a tool to explore the correlation of kinematic variables. Pearson's correlation analysis assessed the positive or negative correlation of the timing and displacement variables of feeding events. In addition, a discriminant analysis was performed to compare and characterize which kinematic variables were best at discriminating between the two otariid species. All statistical tests were conducted using JMP 9.0 (SAS Institute, Cary, NC, USA).

\section{RESULTS}

\section{Frequency of feeding mode and feeding behavior}

Steller sea lions and northern fur seals were divergent in their feeding mode and performance. Overall, Steller sea lions used suction as their primary feeding mode during in-water feeding trials, but also employed a biting feeding mode. The use of suction occurred in $87.4 \%$ of all in-water feeding trials, and a biting feeding mode was employed for the remaining 12.6\% in-water feeding trials. Steller sea lions typically consumed all the fish projecting from the holes first using suction, but occasionally used biting. Fish placed within recessed cylinders were consumed with suction or a combination of suction and hydraulic jetting. During suction events, it was clear that Steller sea lions used the soft tissue of the lips to facilitate suction performance. That is, lateral gape was occluded by contraction of the lateral lips (presumably the m. orbicularis oris and m. buccinator) and the rostral lips were pursed to create a circular orifice. During suction events, gape and gape angle were minimal and a cranial-to-caudal wave of motion in the gular region indicated hyolingual movement (depression and retraction). After food was presumably ingested, often water was observed to be forced out of the corners of the mouth. This was evident by a stream of bubbles leaving this location.

Hydraulic jetting utilized these same kinematic indicators except that the hyolingual apparatus was protracted (i.e. a caudal-to-cranial motion). Suction and hydraulic jetting were used alternately to remove difficult pieces of fish from recessed cylinders, particularly from a cylinder that was partially occluded. However, independent use of hydraulic jetting was observed. During these events, food items were observed to move back and forth within the recessed cylinder and fish pieces were observed exiting the back of the recessed cylinder through the drilled hole. Subjects became proficient at consuming all fish pieces, regardless of whether they were recessed or not.

In contrast to Steller sea lions, northern fur seals used a biting feeding mode exclusively (100\% of all in-water and on-land feeding events). None of the classic kinematic indicators of suction were observed. Instead, classic kinematic indicators of biting dominated. That is, gape and gape angle were wide, lateral gape was not occluded by the lateral lips during feeding events, and the rostral lips were not pursed. In fact, the lips often curled back to expose the teeth. Minimal hyolingual movement was measured and during feeding events there was no indication of movement of prey items within the recessed cylinders. Northern fur seals were never able to extract pieces of fish from within the recessed cylinders. Furthermore, of the 223 pressure recording events there were no subambient or suprambient pressure changes during feeding events that met the criteria for inclusion in data analysis.

During biting events, northern fur seals were occasionally observed to strike at food items projecting from the holes. That is, the head and neck were retracted in an ' $S$ ' shape and the head and open mouth would rapidly be extended forward as the mouth and the teeth closed down upon the food item. However, upon closer inspection we discovered that this 'striking' behavior was actually an aquatic form of inertial transport of food. Northern fur seals would extend their neck while opening their jaws, bite down on an exposed piece of fish, grab it with their teeth and retract their head to remove it from the apparatus. Next, northern fur seals would open their jaws again and move their head and jaws over the piece of fish now suspended in the water column, and close their jaws upon the food once again. These movements produced the characteristic ' $S$ ' shape of the head and neck. This behavior was repeated until the food item was positioned in the back of the buccal cavity, at which time it was swallowed. Occasionally, once the food item was placed near the oropharynx, movement into the esophagus by suction was evident. This visualization was possible because of the large gapes associated with the biting kinematics displayed by northern fur seals. These minor ingestion events always occurred away from the feeding apparatus and the pressure transducer. Even so, it would be technically difficult to measure subambient pressure at this location and any subambient pressure generated is likely minimal. Steller sea lions also exhibited some striking behavior both in water and on land. However, these behaviors in Steller sea lions were not as exaggerated as observed in northern fur seals.

Unlike reports for other marine vertebrates (Marshall et al., 1998, 2003, 2008, 2012, 2014a,b; Bloodworth and Marshall, 2005; Kane 
and Marshall, 2009), northern fur seals often kept their eyes open during feeding events. It was apparent that northern fur seals could observe food items within the recessed cylinders; most subjects made several attempts to obtain those food items from the opposite side of the acrylic. Northern fur seals often attempted to grab fish pieces within recessed wells with their teeth and would use their canines to gnaw around the edges of the recessed cylinder (and pressure transducer) in an attempt to extract a piece of fish. On-land feeding trials elicited only biting behavior $(100 \%)$ by both species. Biting events on land involved subjects grasping projecting fish items with their teeth, removing them from the apparatus and ingesting the food, often using inertial transport. Occasionally, fish were bitten in half and consumed, leaving pieces of fish in the apparatus.

\section{Kinematic analyses of feeding}

Four feeding phases were observed regardless of feeding mode: (I) preparatory, (II) jaw opening, (III) gular depression and (IV) jaw closing. Following Marshall et al. (2008, 2014a), phase I began at the onset of jaw opening and ended when gape increased by greater than $0.2 \mathrm{~cm}$ field ${ }^{-1}$ ( 1 field $=60 \mathrm{~Hz}$ ) and the jaws rapidly opened. Phase II began when gape increased by $\geq 0.2 \mathrm{~cm} \mathrm{field}^{-1}$ and persisted until maximum gape. Phase III began when gular depression increased by $\geq 0.2 \mathrm{~cm}_{\text {field }}{ }^{-1}$. This phase overlapped with phases II and IV, persisted the longest in duration, and concluded when gular depression returned to its original position, which was often at the end of the feeding event. Phase IV began at maximum gape and concluded when the jaws closed. During feeding events, maximum gular depression always followed, or coincided with, maximum gape.

\section{Northern fur seal feeding kinematics}

Northern fur seal feeding kinematics were dominated by a biting mode both in water and on land (Tables 1, 2, Figs 3, 4). This behavior allowed us to investigate for the first time whether a single feeding mode is stereotypical or varies depending upon location. Overall, biting kinematics did not differ significantly between locations, with the exception of (1) a significantly smaller maximum gape angle in water $(47.4 \pm 11.27 \mathrm{deg})$ compared with that on land (54.8 $\pm 12.76 \mathrm{deg}, P<0.048$; Table 2$)$, (2) a significantly slower maximum GAOV in water $\left(622.3 \pm 214.12 \mathrm{deg} \mathrm{s}^{-1}\right)$ compared with that on land (766.8 $\left.\pm 243.19 \mathrm{deg} \mathrm{s}^{-1} ; P<0.003\right)$, and (3) a longer time to maximum GAOV in water $(0.07 \pm 0.041 \mathrm{~s})$ compared with that on land $(0.05 \pm 0.042 \mathrm{~s} ; P<0.002)$. Feeding cycle duration was not significantly different between locations.

\section{Steller sea lion feeding kinematics}

Steller sea lion feeding kinematics differed depending upon feeding mode (Tables 1, 3, Figs 3, 4). Suction feeding was characterized by a significantly smaller maximum gape $(2.9 \pm 0.75 \mathrm{~cm} ; P<0.001)$, smaller maximum gape angle $(12.7 \pm 4.04 \mathrm{deg} ; P<0.001)$, slower maximum GAOV $\left(162.9 \pm 82.4 \mathrm{deg} \mathrm{s}^{-1} ; P<0.001\right)$, slower maximum GACV $\left(144.0 \pm 56.4 \mathrm{deg} \mathrm{s}^{-1} ; P<0.001\right)$ and greater maximum gular depression $(2.6 \pm 0.81 \mathrm{~cm} ; P<0.001)$ compared with a biting feeding mode. Maximum time to GAOV was significantly longer $(0.06 \pm$ $0.03 \mathrm{~s} ; P<0.015)$ for suction feeding compared with biting feeding mode; all other timing variables, including feeding cycle duration, were not significantly different for suction versus biting feeding modes.

\section{Comparative kinematics}

Kinematic variables of both species, location of feeding events and the interaction of species $\times$ location are summarized in Table 1 . Comparative analyses generally demonstrated that Steller sea lions exhibited smaller gape, smaller gape angle and slower GAOV in water versus on land, and that these events were usually smaller and slower compared with those of northern fur seals (Table 1, Figs 3,4$)$. These results are generally consistent with suction versus biting feeding modes. More specifically, the mean feeding cycle duration did not differ significantly between species, location or the interaction of species $\times$ location. Steller sea lions in water displayed a significantly smaller maximum gape compared with Steller sea lions on land and northern fur seals at either location $(P<0.001)$. Steller sea lions displayed a significantly smaller maximum gape angle and slower maximum GAOV than northern fur seals, but there were significant differences in species $\times$ location that resulted in four groups such that Steller sea lions in water $<$ Steller sea lions on land $<$ northern fur seals in water $<$ northern fur seals on land $(P<0.001)$. GACV was significantly slower in Steller sea lions than in northern fur seals at the species level regardless of location $(P<0.001)$. Gular depression was significantly greater in Steller sea lions than in northern fur seals $(P<0.001)$. Timing kinematic variables did not exhibit significant differences in the species $\times$ location interaction term. Some specific differences occurred between species or between locations, but no clear patterns related to the timing of kinematic events emerged.

Gape and gape angle during suction or biting events were significantly less than maximum biological gape and gape angle $(P<0.001)$. Mean maximum biological gape was $16.6 \pm 2.5 \mathrm{~cm}$ and gape angle was $88.3 \pm 5.7 \mathrm{deg}$ for all Steller sea lions. For northern fur seals, mean maximum biological gape was $9.4 \pm 0.2 \mathrm{~cm}$ and

Table 1. Summary of kinematic variables

\begin{tabular}{|c|c|c|c|c|c|}
\hline \multirow[b]{2}{*}{ Kinematic variable } & \multicolumn{2}{|l|}{ Steller sea lions } & \multicolumn{2}{|c|}{ Northern fur seals } & \multirow{2}{*}{$\frac{P}{\text { Species, location, species } \times \text { location }}$} \\
\hline & In water & On land & In water & On land & \\
\hline Maximum gape (cm) & $2.9 \pm 0.75^{a}$ & $4.1 \pm 1.26^{b}$ & $4.34 \pm 1.02^{b}$ & $4.4 \pm 0.94^{b}$ & $P<0.001, P<0.001, P<0.001$ \\
\hline Time to maximum gape (s) & $0.1 \pm 0.05^{a, b}$ & $0.1 \pm 0.051^{\mathrm{a}}$ & $0.1 \pm 0.04^{\mathrm{b}}$ & $0.1 \pm 0.03^{a, b}$ & $P<0.062, P<0.153, P=0.564$ \\
\hline Maximum gape angle (deg) & $12.7 \pm 4.04^{a}$ & $20.0 \pm 5.60^{b}$ & $47.7 \pm 11.27^{\mathrm{c}}$ & $54.8 \pm 12.76^{\mathrm{d}}$ & $P<0.001, P<0.001, P=0.902$ \\
\hline Time to maximum gape angle (s) & $0.1 \pm 0.05^{a, b}$ & $0.1 \pm 0.05^{\mathrm{a}}$ & $00.1 \pm 0.04^{b}$ & $0.1 \pm 0.03^{a, b}$ & $P<0.023, P=0.062, P=0.832$ \\
\hline GAOV $\left(\operatorname{deg~s} s^{-1}\right)$ & $162.9 \pm 82.4^{a}$ & $339.9 \pm 141.5^{b}$ & $622.3 \pm 214.12^{c}$ & $766.8 \pm 243.19^{d}$ & $P<0.001, P<0.001, P=0.559$ \\
\hline Time to GAOV (s) & $0.06 \pm 0.03^{a, b}$ & $0.04 \pm 0.029^{a}$ & $0.07 \pm 0.041^{\mathrm{b}}$ & $0.05 \pm 0.042^{a}$ & $P=0.134, P<0.001, P=0.412$ \\
\hline GACV $\left(\operatorname{deg~s}{ }^{-1}\right)$ & $144.0 \pm 56.40^{a}$ & $207.8 \pm 82.09^{a}$ & $408.3 \pm 145.52^{b}$ & $443.4 \pm 156.53^{b}$ & $P<0.001, P<0.006, P=0.425$ \\
\hline Time to GACV (s) & $0.15 \pm 0.057^{\mathrm{a}}$ & $0.2 \pm 0.065^{\mathrm{a}, \mathrm{b}}$ & $0.18 \pm 0.052^{\mathrm{b}}$ & $0.20 \pm 0.053^{b}$ & $P<0.001, P=0.066, P=0.871$ \\
\hline Gular depression (cm) & $2.6 \pm 0.81^{a}$ & $1.9 \pm 0.87^{\mathrm{b}}$ & $0.7 \pm 0.29^{c}$ & $1.48 \pm 0.70^{d}$ & $P<0.001, P=0.428, P<0.001$ \\
\hline Time to gular depression (s) & $0.13 \pm 0.051^{\mathrm{a}, \mathrm{b}}$ & $0.11 \pm 0.047^{\mathrm{a}}$ & $0.14 \pm 0.04^{b}$ & $0.13 \pm 0.056^{a, b}$ & $P=0.067, P<0.005, P=0.742$ \\
\hline Feeding cycle duration (s) & $0.28 \pm 0.085^{a}$ & $0.25 \pm 0.067^{\mathrm{a}}$ & $0.27 \pm 0.06^{\mathrm{a}}$ & $0.3 \pm 0.05^{a}$ & $P=0.228, P=0.312, P=0.049$ \\
\hline
\end{tabular}

GAOV, gape angle opening velocity; GACV, gape angle closing velocity.

Values are means \pm s.d., $N=181$. Different superscript letters indicate significant differences among species and locations for each kinematic variable. 
Table 2. Effect of location on biting feeding mode in northern fur seals

\begin{tabular}{|c|c|c|c|}
\hline Kinematic variable & In water & On land & $P$ \\
\hline Maximum gape $(\mathrm{cm})$ & $4.34 \pm 1.02^{\mathrm{a}}$ & $4.4 \pm 0.94^{a}$ & $P=0.969$ \\
\hline Time to maximum gape (s) & $0.1 \pm 0.04^{\mathrm{a}}$ & $0.1 \pm 0.03^{\mathrm{a}}$ & $P=0.443$ \\
\hline Maximum gape angle (deg) & $47.7 \pm 11.27^{\mathrm{a}}$ & $54.8 \pm 12.76^{\mathrm{b}}$ & $P<0.048$ \\
\hline $\begin{array}{l}\text { Time to maximum gape } \\
\text { angle (s) }\end{array}$ & $00.1 \pm 0.04^{\mathrm{a}}$ & $0.1 \pm 0.03^{a}$ & $P=0.172$ \\
\hline GAOV $\left(\operatorname{deg~s}^{-1}\right)$ & 622.3 & $243.19^{b}$ & $P<0.003$ \\
\hline Time to GAOV (s) & 0.07 & 0.05 & $P<0.002$ \\
\hline GACV $\left(\operatorname{deg~s}^{-1}\right)$ & $408.3 \pm 145.52^{\mathrm{a}}$ & $443.4 \pm 156.53^{\mathrm{a}}$ & $P=0.257$ \\
\hline Time to GACV (s) & $0.18 \pm 0.052^{\mathrm{a}}$ & $0.20 \pm 0.053^{\mathrm{a}}$ & $P=0.186$ \\
\hline Gular depression (c & $0.7 \pm$ & $1.48 \pm 0.70^{b}$ & $P<0.001$ \\
\hline Time & 0.14 & $0.13 \pm 0.056^{b}$ & $P<0.038$ \\
\hline Feeding cycle duration (s) & $0.27 \pm 0.06^{a}$ & $0.3 \pm 0.05^{a}$ & $P=0.407$ \\
\hline
\end{tabular}

GAOV, gape angle opening velocity; GACV, gape angle closing velocity. Values are means \pm s.d., $N=96$. Different superscript letters indicate a significant difference between locations for northern fur seal kinematic variables. Significant $P$-values are given in bold.

gape angle was $87.0 \pm 3.5$ deg. Collectively, maximum gape was $12.9 \pm 3.75 \mathrm{~cm}$ and gape angle was $87.3 \pm 5.02 \mathrm{deg}$.

The first four axes of a PC analysis on correlations characterized $72 \%$ of the variation of otariid feeding kinematics $(\mathrm{PC} 1=31.7 \%$, $\mathrm{PC} 2=25.4 \%, \mathrm{PC} 3=8.2 \%, \mathrm{PC} 4=7.5 \%)$. High loadings on $\mathrm{PC} 1$ identified gape angle, GAOV, GACV and gape as important contributions (Table 4). PC2 identified all timing kinematic variables with the exception of time to maximum GAOV and GACV (i.e. time to maximum gape angle, gape and gular depression). PC3 had high negative loadings for GAOV and GACV, and PC4 had high loadings for maximum gular depression and gape, indicating distinct differences in suction versus biting feeding events. Pearson's correlation analysis further supported the difference between suction and biting feeding kinematics. As shown by the PC analysis, the Pearson's correlation analysis demonstrated that most, but not all, kinematic variables were positively correlated. However, gular depression and time to gular depression were distinct in that they were negatively correlated with most kinematic variables.

A linear discriminant analysis of kinematic variables demonstrated that species occupied significantly different canonical space $(P<0.001$; Fig. 4). It correctly classified species by $98.3 \%$, and identified that maximum gape angle, time to maximum gape angle, GAOV and time to GAOV in northern fur seals and small maximum gape and large gular depression in Steller sea lions were the primary kinematic variables that separated the two species.

\section{Suction and hydraulic jetting pressure}

Pressure measurements during feeding events supported the behavioral and kinematic data from both species. The lack of any detectable subambient or suprambient pressure measurements during northern fur seal feeding events further supports our observations that northern fur seals exclusively used a biting feeding mode, and possibly are not capable of generating subambient or suprambient pressures directed in front of the mouth. The pressure data supported our finding that Steller sea lions use suction as their primary feeding mode (subambient pressure generation), but also employed hydraulic jetting (suprambient pressure generation) and a biting feeding mode when feeding in water (Fig. 5). Frequency data from pressure traces show that when Steller sea lions were not biting, they employed suction $87.4 \%$ of the time and hydraulic jetting $13.9 \%$ of the time. Pressure data demonstrate that suction events were initiated by an expansive phase that generated the maximum subambient pressure for that event, followed by a compressive phase, during which pressure returned to baseline levels (Fig. 5). A preparatory phase was not observed in Steller sea lions as found in bearded seals (Marshall et al., 2008). Similarly, pressure data from hydraulic jetting failed to detect a preparatory phase and only demonstrated an expansive phase during which maximum suprambient pressure was recorded, followed by a compressive phase, during which pressure values returned to baseline. The maximum subambient and suprambient pressures recorded were $45 \mathrm{kPa}$.

\section{Vibrissal use}

Mystacial vibrissae were used by both species during all feeding trials regardless of location. During in-water feeding trials, all subjects relied upon active touch sensation using mystacial vibrissae. Subjects were observed to use the largest of the mystacial vibrissae (macrovibrissae) to explore the edges of the feeding apparatus and to locate pieces of fish protruding from holes in the acrylic surface. However, for food held within recessed cylinders, subjects systematically located the center of each cylinder by sweeping the acrylic surface with their most medially located vibrissae (microvibrissae) and allowed these whiskers to protrude into each cylinder. If a food item was still located within a cylinder, these whiskers could often touch it. This would elicit suction or biting behavior and if the food item was difficult to remove, Steller sea lions would then elicit hydraulic jetting behavior, often alternating with suction behavior, until the food item(s) was removed and consumed.

\section{DISCUSSION}

The kinematic and pressure datasets obtained from our study of northern fur seals and Steller sea lions are the largest yet collected for any feeding kinematic and performance study of marine mammals. Unexpectedly, they show the feeding performances of these two species of otariids are divergent from each other. Food acquisition by northern fur seals was constrained to a biting feeding mode, whereas Steller sea lions used both suction and biting feeding modes.

Northern fur seal feeding kinematics was dominated by a large gape, large gape angle, faster GAOV and GACV, and minimal gular depression. Northern fur seals were more stereotypical than Steller sea lions in that a biting mode dominated their feeding repertoire regardless of whether they consumed prey in the water or on land. Gape and gape angle of northern fur seals were larger and their GAOV and GACV were generally faster than those of Steller sea lions. In fact, northern fur seals displayed the greatest gape, gape angle and gape velocities of any marine mammal measured to date. In addition, the absence of pressure generation for prey acquisition (as measured by direct pressure measurement, kinematic gular depression, lip pursing and inability to extract fish from recessed cylinders) implies that northern fur seals are biting specialists, perhaps to the degree that walruses and bearded seals are suction specialists (Fay, 1982; Kastelein et al., 1994; Marshall et al., 2008).

The inertial transport of food items observed in northern fur seals, and to some extent in Steller sea lions, is likely widespread among pinnipeds. Reports of seals and sea lions 'striking' are likely biting attempts followed by head and jaw movements that are really manipulation events related to inertial transport of food within the buccal cavity. The 'jerking' movement of harbor seals detected by accelerometers affixed to their heads may be such an inertial transport behavior (Ydesen et al., 2014). In fact, jerks were recorded 
for prey acquisition using both suction and biting feeding modes. Food items acquired by either mode should elicit such a jerk behavior as captured food or prey is manipulated within the buccal cavity in preparation for swallowing.

Among bony fishes, a biting feeding mode is considered to be ancestral and a much more varied and flexible feeding strategy. However, the biting we observed in northern fur seals seemed stereotypical. In contrast, suction feeding, as observed in Steller sea lions, requires a series of morphological parts and behavioral events to be coordinated to function effectively (Collar et al., 2014). Such functional integration likely constrains skull evolution and suction feeding (Collar et al., 2014). It has been suggested that the terrestrial arctoid ancestors of pinnipedimorphs (pinnipeds and their extinct relatives) exhibited a biting feeding mode, and biting is considered the ancestral feeding mode among extant pinnipeds (Werth, 2000a; Adam and Berta, 2002; Berta et al., 2006). However, functional data have not been available to validate this hypothesis.

Recent studies (that include both morphological and molecular data) have consistently positioned northern fur seals as the most basal living otariid, and in most instances Steller sea lions either as a sister group or still basal relative to other otariids (Arnason et al., 2006; Higdon et al., 2007; Yonezawa et al., 2009; Berta and Churchill, 2012; Churchill et al., 2014). The sole use of a biting feeding mode by northern fur seals suggests that they exhibit their ancestral feeding mode. Northern fur seals differ from all other species for which feeding performance studies of marine mammals are available (e.g. Kastelein et al., 1994; Werth, 2000b; Bloodworth and Marshall, 2005; Marshall et al., 2008, 2014a; Kane and Marshall, 2009; Hocking et al., 2013, 2014). To date, performance data among pinnipeds (phocids and otariids) suggest that a suction feeding mode or a mixed feeding mode dominates, not a biting feeding mode. While Australian sea lions appear to use a biting feeding mode more extensively, suction is also used extensively depending upon how food is presented (Hocking et al., 2014). Data from Australian sea lions (Arctocephalus pusillus doriferus) corroborates our findings here for Steller sea lions, in which this species uses both suction and biting feeding modes. Further evidence that northern fur seal feeding differs from that of other otariids and

Gape (cm)
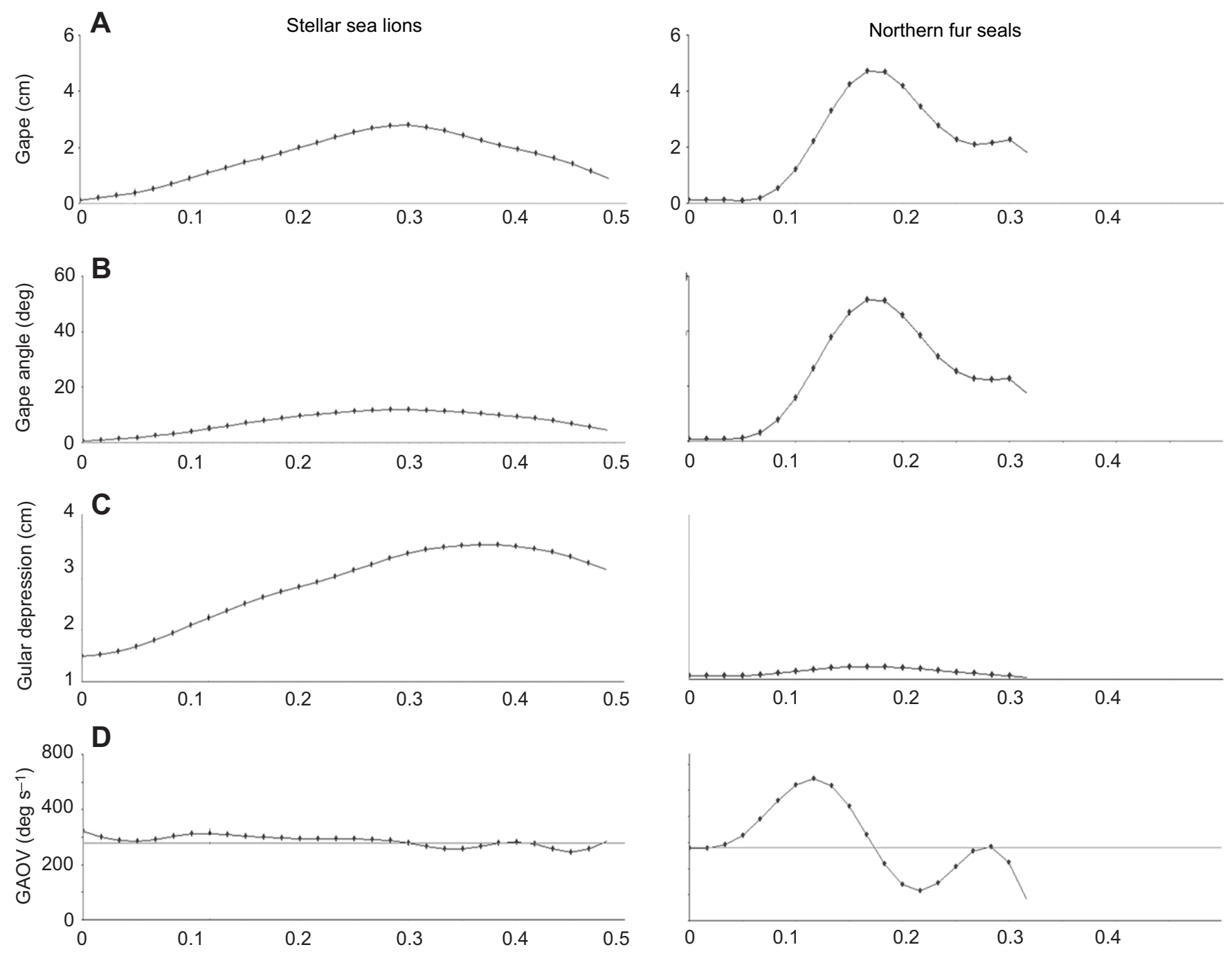

Time (s)

Fig. 3. Representative kinematic profiles of Steller sea lions versus northern fur seals feeding in water. (A) Gape, (B) gape angle, (C) gular depression and (D) gape angle opening velocity (GAOV). Note that all axes are scaled to facilitate comparison. 


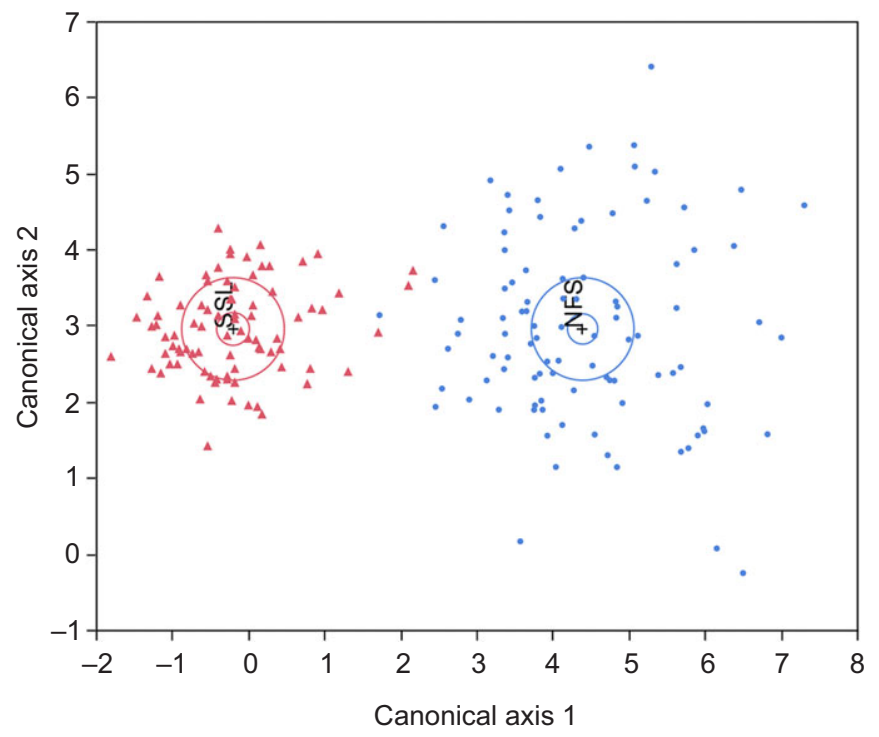

Fig. 4. Canonical plot based on linear discriminant analyses of Steller sea lion and northern fur seal kinematic variables. Each species (SSL, Steller sea lion; NFS, northern fur seal) occupies distinct canonical space due to differences of feeding kinematics.

pinnipeds is provided by the craniodental disparity between northern fur seals and Steller sea lions. While neither of these species exhibit the classical elongate rostra and 'pincer' jaws (sensu Werth, 2000a) of a biting feeding mode (exemplified in odontocetes), relative to Steller sea lions, northern fur seals possess narrow skulls, gracile pterygoid hamuli, a small hyoid apparatus, small triangular cuspate post-canine teeth (and canines) that are vertically oriented (erect), and a short post-canine tooth row, which is unusual among extant otariids (Adam and Berta, 2002; Brunner, 2004; Boessenecker, 2011; C.D.M., unpublished data). Externally, northern fur seals have a distinct rostrum. All of these morphological features indicate a divergent feeding strategy, as confirmed in this study.

The genus Callorhinus (Callorhinus gilmorei+Callorhinus sp. + Callorhinus ursinus) is the oldest and earliest diverging crown otariid; the antiquity of this lineage spans back to the Pliocene (Boessenecker, 2011). There is strong evidence that Callorhinus represents an anagenic lineage and that $C$.gilmorei and Callorhinus sp. exhibit a craniodental morphological continuum with $C$. ursinus (Kohno and Yanagisawa, 1997; Boessenecker, 2011). Therefore, if a biting feeding mode is dominant in extant Callorhinus, then through functional inference we can assign a biting feeding mode to extinct species of Callorhinus (i.e. C. gilmorei and Callorhinus sp.). Furthermore, since northern fur seals are consistently positioned as the most basal living otariid phylogenetically (Wynen et al., 2001; Arnason et al., 2006; Higdon et al., 2007; Dasmahapatra et al., 2009; Wolf et al., 2007; Yonezawa et al., 2009; Berta and Churchill, 2012), this supports our hypothesis that C. ursinus exhibits its ancestral feeding mode. New discoveries of transitional fossils, subsequent craniodental analyses (e.g. Boessenecker et al., 2011) and functional data from both extant and fossil pinnipeds are needed to explore this functional hypothesis further.

Biting has been estimated or measured directly in a variety of vertebrate taxa (e.g. Kiltie, 1982; Thomason, 1991; Binder and Van Valkenburgh, 2000; Huber et al., 2005; Wroe et al., 2005; Christiansen and Wroe, 2007; Christiansen, 2008; Ellis et al., 2008, 2009; Davis et al., 2010; Mara et al., 2010; Marshall et al., $2012,2014 b)$. In general, bite force in terrestrial mammals is related to body size, aspects of craniodental morphology, biomechanics and feeding ecology. Carnivores feeding on large prey, or on tough plant material, generally have higher bite forces than insectivores; taxa feeding on small prey have relatively moderate bite forces (Christiansen and Wroe, 2007). The large body size of pinnipeds implies that they should have a high bite force, but the relatively small size of their prey would suggest they have moderate bite forces. However, prey size in pinnipeds is variable. Many pinniped taxa consume small fishes and cephalopods (King, 1983; Riedman, 1990; Pauly et al., 1998), but some species feed on invertebrates (including bivalves, which are hard prey items), while some feed on large avian (e.g. penguins) and mammalian prey (other marine mammals). The capability to take large fish, and other large prey, should require a strong bite force.

Northern fur seals feed on a wide variety of small mesopelagic fishes (e.g. smoothtongue and lanternfish), schooling fishes (e.g. herring and anchovy), as well as walleye pollock, sand lance, capelin and several species of squid (Antonelis et al., 1997; Mori et al., 2001). Juvenile walleye pollock (Theragra chalcogramma) and gonatid squid are of particular importance during the summer and autumn in the eastern Bering Sea (Sinclair et al., 1994). Northern fur seals tend to feed at dusk and dawn, and dive to the deep scattering layer to feed on these small mesopelagic fishes (Gentry and Johnson, 1981; Gentry et al., 1986), including juvenile walleye pollock and Atka mackerel (Gentry and Johnson, 1981; Gentry et al., 1986; Benoit-Bird et al., 2013). It is unclear whether feeding in a pelagic habitat in pursuit of small elusive fish and squid is more successful using a ram-biting strategy and inertial transport rather than a suction feeding mode. Although suction feeding is

Table 3. Comparison of feeding mode in Steller sea lions

\begin{tabular}{|c|c|c|c|}
\hline Kinematic variable & Suction & Biting & $P$ \\
\hline Maximum gape (cm) & $2.9 \pm .75^{a}$ & $4.1 \pm 1.26^{b}$ & $P<0.001$ \\
\hline Time to maximum gape (s) & $0.1 \pm 0.05^{\mathrm{a}}$ & $0.1 \pm 0.051^{\mathrm{a}}$ & $P=0.245$ \\
\hline Maximum gape angle (deg) & $12.7 \pm 4.04^{a}$ & $20.0 \pm 5.60^{b}$ & $P<0.001$ \\
\hline Time to maximum gape angle (s) & $0.1 \pm 0.05^{a}$ & $0.1 \pm 0.05^{a}$ & $P=0.200$ \\
\hline GAOV $\left(\operatorname{deg~s} s^{-1}\right)$ & $162.9 \pm 82.4^{a}$ & $339.9 \pm 141.5^{b}$ & $P<0.001$ \\
\hline Time to GAOV (s) & $0.06 \pm 0.03^{a}$ & $0.04 \pm 0.029^{b}$ & $P<0.015$ \\
\hline GACV $\left(\operatorname{deg~s}{ }^{-1}\right)$ & $144.0 \pm 56.40^{\mathrm{a}}$ & $207.8 \pm 82.09^{b}$ & $P<0.001$ \\
\hline Time to GACV (s) & $0.15 \pm 0.057^{a}$ & $0.2 \pm 0.065^{a}$ & $P=0.204$ \\
\hline Gular depression (cm) & $2.6 \pm 0.81^{a}$ & $1.9 \pm 0.87^{b}$ & $P<0.001$ \\
\hline Time to gular depression (s) & $0.13 \pm 0.051^{a}$ & $0.11 \pm 0.047^{a}$ & $P<0.059$ \\
\hline Feeding cycle duration (s) & $0.28 \pm 0.085^{a}$ & $0.25 \pm 0.067^{a}$ & $P=0.076$ \\
\hline
\end{tabular}

GAOV, gape angle opening velocity; GACV, gape angle closing velocity.

Values are means \pm s.d., $N=85$. Different superscript letters indicate significant differences between feeding modes for Steller sea lion kinematic variables. Significant $P$-values are given in bold. 
Table 4. Principal component loading matrix

\begin{tabular}{|c|c|c|c|c|}
\hline Kinematic variable & PC1 (31.7\%) & PC2 (25.4\%) & PC3 $(8.2 \%)$ & PC4 $(7.5 \%)$ \\
\hline Maximum gape (cm) & 0.65030 & -0.27023 & -0.00829 & 0.51523 \\
\hline Time to maximum gape (s) & 0.44743 & 0.76412 & 0.01283 & -0.06969 \\
\hline Maximum gape angle (deg) & 0.91953 & -0.27249 & 0.10864 & 0.04261 \\
\hline Time to maximum gape angle (s) & 0.41028 & 0.79993 & 0.06465 & -0.03995 \\
\hline Gape angle opening velocity $\left(\operatorname{deg~s}^{-1}\right)$ & 0.74395 & -0.50721 & 0.17729 & 0.03613 \\
\hline Time to gape angle opening velocity (s) & 0.25008 & 0.48581 & -0.55447 & -0.07832 \\
\hline Gape angle closing velocity $\left(\operatorname{deg~} \mathrm{s}^{-1}\right)$ & 0.78547 & -0.31909 & 0.04149 & -0.15591 \\
\hline Time to gape angle closing velocity (s) & 0.45710 & 0.38012 & -0.41841 & 0.34728 \\
\hline Gular depression (cm) & -0.58588 & 0.19203 & 0.18157 & 0.62584 \\
\hline Time to gular depression (s) & 0.17827 & 0.59091 & 0.40488 & 0.03151 \\
\hline Feeding cycle duration (s) & 0.17708 & 0.54267 & 0.41150 & -0.05184 \\
\hline
\end{tabular}

often associated with teuthophagy in odontocetes (toothed-whales; Werth, 2000b), in an open mesopelagic environment it is questionable how successful a suction feeding mode may be, because of the functional trade-off between subambient pressure generation and effective distance using suction (Higham et al., 2006; Marshall et al., 2008, 2014a). Clearly, odontocetes are using different tactics from those employed by pinnipeds. There is historical evidence supporting the effectiveness of a biting feeding mode in mesopelagic habitats. Morphological and paleoecological data indicate that a ram-biting feeding mode, but not a suction feeding mode, was predominant among Triassic ichthyosaurs, even those feeding in mesopelagic habits (Motani et al., 2013; Pyenson et al., 2014). It is not certain whether a biting feeding mode in northern fur seals was driven by ecological pressures or phylogenetic constraint.

The Steller sea lions in our study exhibited a rich feeding repertoire that included both biting and suction feeding modes. Furthermore, they often alternated suction with hydraulic jetting when challenged with prey items that were difficult to acquire. Steller sea lion feeding kinematics and performance, and the use of using hydraulic jetting (either on its own or alternated with suction), was similar to behavior documented previously for bearded seals (Marshall et al., 2008), walruses (Fay, 1982; Kastelein and Mosterd, 1989; Kastelein et al., 1994), leopard seals (Hocking et al., 2013), harbor seals (Marshall et al., 2014a) and Australian fur seals

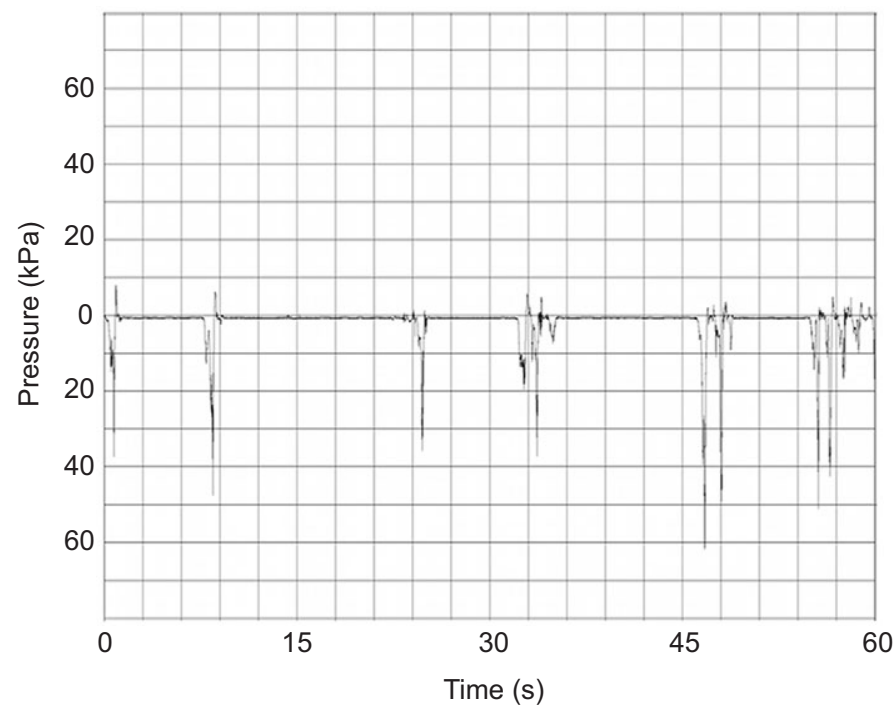

Fig. 5. Pressure trace of a representative Steller sea lion during subambient pressure generation events.
(Hocking et al., 2014). The use of suction and hydraulic jetting by Steller sea lions converges with other pinnipeds (Marshall et al., 2008, 2014a; Hocking et al., 2013), pygmy and dwarf sperm whales (Bloodworth and Marshall, 2005), belugas (Kane and Marshall, 2009) and pilot whales (Werth, 2000b; Kane and Marshall, 2009). Hydraulic jetting performance in Steller sea lions supports the functional hypothesis that this behavior is similar to suction generation (Reidenberg and Laitman, 1994), but with the tongue and hyoid elevated (using different sets of muscles compared with those for suction) instead of retracted, to produce suprambient pressures rather than subambient pressures (Marshall et al., 2008, 2014a).

The maximum subambient and maximum suprambient pressures generated by our Steller sea lions were similar in magnitude $(45 \mathrm{kPa}$ each) to those of harbor seals (48.6 and $53.9 \mathrm{kPa}$, respectively; Marshall et al., 2014a). Although both of these species can create significant subambient pressure, their performance is not at the same level as pinniped suction feeding specialists such as bearded seals (91.2 kPa; Marshall et al., 2008) and walruses (91.2 kPa; Fay, $1982 ; 118 \mathrm{kPa}$; Kastelein et al., 1994). Instead, the feeding performance of Steller sea lions was indicative of a generalist forager that used either a suction or biting feeding mode, but preferred suction feeding at a similar frequency to that reported for harbor seals (Marshall et al., 2014a). As with other suction feeding marine mammals, small gape, small gape angle and greater gular depression were used in conjunction with occlusion of lateral gape and pursing of the rostral lips to form an aperture that functioned to increase suction feeding performance (increased subambient pressure; Bloodworth and Marshall, 2005, 2007; Marshall et al., 2008, 2014a; Kane and Marshall, 2009).

Steller sea lions have a broad diet and are considered to be opportunistic predators. They feed on both small schooling fishes (e.g. herring) as well as large demersal fishes (e.g. rockfishes). Their diet includes: walleye pollock, mackerel, salmonids, sand lance, flatfish, cod and sculpins. They also consume squid, octopus, and pups of northern fur seals, harbor seals and sea otters (Pauly et al., 1998; Sinclair and Zeppelin, 2002; Trites et al., 2007). Whereas a suction feeding mode may be advantageous for consuming cephalopods and small fishes, the taking of pups and large fish, and the large size of their skulls and mandibles suggests that Steller sea lions are capable of large bite forces. Having a diversity of feeding modes would be important for a generalist forager such as Steller sea lions. Suction and biting feeding modes are thus both important components of their feeding repertoire.

Performance data suggest that suction, rather than biting as suggested by Adam and Berta (2002), is the dominant feeding mode used by pinnipeds. This should not be surprising given that suction feeding is an effective and widespread feeding mode among aquatic 
vertebrates (Lauder, 1985; Wainwright et al., 2015). In fact, some level of suction feeding is represented in all groups of aquatic vertebrates, and is well studied among fishes (e.g. Liem, 1978; Lauder, 1980; Osse and Muller, 1980; Bemis, 1987; Motta, 1984; Wilga et al., 2000; Motta and Wilga, 2001). Suction generation in marine mammals occurs by the rapid depression and retraction of the hyolingual apparatus (Werth, 2000a, 2007). Kinematic and feeding performance studies in odontocetes (Bloodworth and Marshall, 2005; Kane and Marshall, 2009) and phocid pinnipeds (Marshall et al., 2008, 2014a) support this functional hypothesis, but suction-generating mechanisms in marine mammals may be more diverse than previously thought.

The suction generated by the Steller sea lions in our study is likely typical of how other marine mammals generate subambient pressures. Although Steller sea lions employed several of the same mechanisms to generate subambient pressures, they did not employ a preparatory phase for suction as found in bearded seals. In bearded seals, this phase likely increases the change in intraoral volume that is related to greater subambient pressure development. Neither Steller sea lions nor northern fur seals possess a vaulted palate as observed in other pinnipeds specialized for suction generation. Rapid jaw depression can often be used to generate suction (Wainwright et al., 2015). In the case of pinnipeds, rapid jaw opening (as measured by GAOV) can also contribute to subambient pressure generation via further buccal expansion in conjunction with hyolingual depression. However, Steller sea lion feeding kinematics and performance did not support our working functional hypothesis that rapid jaw opening is correlated with suction feeding in this species, as observed in bearded seals and pygmy and dwarf sperm whales (Bloodworth and Marshall, 2005; Marshall et al., 2008). This mechanism appears to be constrained to marine mammals that are specialist suction feeders such as pygmy sperm whales $\left(\mathrm{GAOV}=293 \mathrm{deg} \mathrm{s}^{-1}\right.$; Bloodworth and Marshall, 2005) and bearded seals (GAOV=205 deg s ${ }^{-1}$; Marshall et al., 2008). By comparison, the mean maximum GAOV of Steller sea lions in our study was $\sim 163 \mathrm{deg} \mathrm{s}^{-1}$, less than that reported for harbor seals $\left(\sim 197 \mathrm{deg} \mathrm{s}^{-1}\right)$. Jaw opening velocities of Steller sea lions add to the growing dataset indicating that not all suction feeding specialists employ rapid jaw depression (i.e. belugas, $\mathrm{GAOV}=119 \mathrm{deg} \mathrm{s}^{-1}$ ). In fact, the GAOV of northern fur seals, which is the fastest recorded of any marine mammal to date (622 deg $\mathrm{s}^{-1}$ ), did not produce any measurable subambient pressure events, indicating the importance of orofacial morphology and lip pursing to occlude lateral gape and create an aperture at the rostral lips (Bloodworth and Marshall, 2005, 2007; Marshall et al., 2014a; this study).

Data from our study show that northern fur seals exhibit a single feeding mode, while Steller sea lions have a broader repertoire of feeding strategies that include biting, suction and hydraulic jetting. Behavioral observations also showed that, like harbor seals, Steller sea lions were flexible in their use of multiple feeding modes to extract food items from the feeding apparatus. Such flexibility of feeding strategies likely forms the basis of their opportunistic, generalized feeding ecology. Steller sea lion kinematics and performance were similar to those of both harbor seals and bearded seals. However, both Steller sea lions and harbor seals lack certain specialized suction feeding behaviors (i.e. lack of a preparatory phase prior to suction feeding and slower jaw depression). Behavioral video data of wild Steller sea lions foraging (Olivier, 2015) suggest they use a suction feeding mode near ledges and rocky benthic habitat. Like harbor seals and bearded seals, it is probable that they also use the substrate and the geometry of the habitat to passively increase their suction capability, as found in chondrichthyan and teleost fishes (Carroll et al., 2004; Nauwelaerts et al., 2007).

\section{Acknowledgements}

We thank Brandon Russell for assisting in constructing and installing the feeding apparatus. Thanks to Allyson Hindle for organizing work at the UBC Open Water facility. We appreciate the assistance of all the Vancouver Aquarium pinniped trainers, as well as the assistance from Meghan Walker and Caitlin Sprowls with pressure measurements and kinematic analyses, respectively.

\section{Competing interests}

The authors declare no competing or financial interests.

\section{Author contributions}

C.D.M. designed, collected and supervised the data analyses. D.A.S.R. assisted in the design of the feeding apparatus and data collection. A.W.T. provided access to animals and animal training. C.D.M., D.A.S.R. and A.W.T. prepared the manuscript and figures

\section{Funding}

Funding of international travel to C.D.M. was provided by Texas A\&M University as part of Faculty Development Leave.

\section{References}

Adam, P. J. and Berta, A. (2002). Evolution of prey capture strategies and diet in the Pinnipedimorpha (Mammalia, Carnivora). Oryctos 4, 83-107.

Antonelis, G. A., Sinclair, E. H., Ream, R. R. and Robson, B. W. (1997). Interisland variation in the diet of female northern fur seals (Callorhinus ursinus) in the Bering Sea. J. Zool. 242, 435-451.

Arnason, U., Gullberg, A., Janke, A., Kullberg, M., Lehman, N., Petrov, E. A. and Väinölä, R. (2006). Pinniped phylogeny and a new hypothesis for their origin and dispersal. Mol. Phylogenet. Evol. 41, 345-354.

Arnold, S. J. (1983). Morphology, performance and fitness. Amer. Zool. 23, 347-361.

Bemis, W. E. (1987). Feeding systems of living Dipnoi: anatomy and function. In The Biology and Evolution of Lungfishes (ed. W. E. Bemis, W. W. Berggren and N. E. Kemp), pp. 249-275. New York: Alan R Liss.

Benoit-Bird, K. J., Battaile, B. C., Nordstrom, C. A. and Trites, A. W. (2013). Foraging behavior of northern fur seals closely matches the hierarchical patch scales of prey. Mar. Ecol. Prog. Ser. 479, 283-302

Berta, A. and Churchill, M. (2012). Pinniped taxonomy: review of currently recognized species and subspecies, and evidence used for their description. Mamm. Rev. 42, 207-234

Berta, A., Sumich, J. L. and Kovacs, K. M. (2006). Marine Mammals: Evolutionary Biology, 2nd edn. San Diego: Academic Press.

Binder, W. J. and Van Valkenburgh, B. (2000). Development of bite strength and feeding behaviour in juvenile spotted hyenas (Crocuta crocuta). J. Zool. 252 273-283.

Bloodworth, B. and Marshall, C. D. (2005). Feeding kinematics of Kogia and Tursiops (Odontoceti: Cetacea): characterization of suction and ram feeding. J. Exp. Biol. 208, 3721-3730.

Bloodworth, B. E. and Marshall, C. D. (2007). A functional comparison of the hyolingual complex in pygmy and dwarf sperm whales (Kogia breviceps and K. sima), and bottlenose dolphins (Tursiops truncatus). J. Anat. 211 78-91.

Boessenecker, R. W. (2011). New records of the fur seal Callorhinus (Carnivora: Otariidae) from the Plio-Pleistocene Rio Dell Formation of northern California and comments on otariid dental evolution. J. Vertebr. Paleontol. 31, 454-467.

Bowen, W. D., Tully, D., Boness, D. J., Bulheier, B. M. and Marshall, G. J. (2002) Prey-dependent foraging tactics and prey profitability in a marine mammal. Mar. Ecol. Prog. Ser. 244, 235-245.

Brunner, S. (2004). Fur seals and sea lions (Otariidae): identification of species and taxonomic review. Syst. Biodivers. 1, 339-439.

Carroll, A. M., Wainwright, P. C., Huskey, S. H., Collar, D. C. and Turingan, R. G. (2004). Morphology predicts suction feeding performance in centrarchid fishes. J. Exp. Biol. 207, 3873-3881.

Christiansen, P. (2008). Evolution of skull and mandible shape in cats (Carnivora: Felidae). PLoS ONE 3, e2807.

Christiansen, P. and Wroe, S. (2007). Bite forces and evolutionary adaptations to feeding ecology in carnivores. Ecology 88, 347-358.

Churchill, M., Boessenecker, R. W. and Clementz, M. T. (2014). Colonization of the Southern Hemisphere by fur seals and sea lions (Carnivora: Otariidae) revealed by combined evidence phylogenetic and Bayesian biogeographical analysis. Zool. J. Linn. Soc. 172, 200-225. 
Collar, D. C., Wainwright, P. C., Alfaro, M. E., Revell, L. J. and Mehta, R. S. (2014). Biting disrupts integration to spur skull evolution in eels. Nat. Commun. $\mathbf{5}$ 5505.

Dasmahapatra, K. K., Hoffman, J. I. and Amos, W. (2009). Pinniped phylogenetic relationships inferred using AFLP markers. Heredity 103, 168-177.

Davis, J. L., Santana, S. E., Dumont, E. R. and Grosse, I. R. (2010). Predicting bite force in mammals: two-dimensional versus three-dimensional lever models. J. Exp. Biol. 213, 1844-1851.

Demére, T. A. and Berta, A. (2005). New skeletal material of Thalassoleon (Otariidae: Pinnipedia) from the late Miocene-early Pliocene (Hemphillian) of California. Bull. Fla. Mus. Nat. Hist. 45, 379-411.

Ellis, J. L., Thomason, J. J., Kebreab, E. and France, J. (2008). Calibration of estimated biting forces in domestic canids: comparison of post-mortem and in vivo measurements. J. Anat. 212, 769-780.

Ellis, J. L., Thomason, J. J., Kebreab, E., Zubair, K. and France, J. (2009). Cranial dimensions and forces of biting in the domestic dog. J. Anat. 214 362-373.

Emlen, J. M. (1966). The role of time and energy in food preference. Am. Nat. 100, 611-617.

Fay, F. H. (1982). Ecology and Biology of the Pacific Walrus, Odobenus rosmarus divergens Illiger, 279 p. Washington, DC: United States Fish and Wildlife Service Publication Number. 74.

Gentry, R. L. and Johnson, J. H. (1981). Predation by sea lions on northern fur seal neonates. Mammalia 45, 423-430.

Gentry, R. L., Kooyman, G. L. and Goebel, M. E. (1986). Feeding and diving behavior of northern fur seals. In Fur Seals: Maternal Strategies on Land and at Sea (ed. R. L. Gentry and G. L. Kooyman), pp. 61-78. Princeton: Princeton University Press.

Higdon, J. W., Bininda-Emonds, O. R. P., Beck, R. M. D. and Ferguson, S. H (2007). Phylogeny and divergence of the pinnipeds (Carnivora: Mammalia) assessed using a multigene dataset. BMC Evol. Biol. 7, 216.

Higham, T. E., Day, S. W. and Wainwright, P. C. (2006). The pressures of suction feeding: the relation between buccal pressure and induced fluid speed in centrarchid fishes. J. Exp. Biol. 209, 3281-3287.

Hocking, D. P., Evans, A. R. and Fitzgerald, E. M. G. (2013). Leopard seals (Hydrurga leptonyx) use suction and filter feeding when hunting small prey underwater. Polar Biol. 36, 211-222.

Hocking, D. P., Salverson, M., Fitzgerald, E. M. G. and Evans, A. R. (2014). Australian Fur seals (Arctocephalus pusillus doriferus) use raptorial biting and suction feeding when targeting prey in different foraging scenarios. PLOS ONE 9, e112521.

Huber, D. R., Eason, T. G., Hueter, R. E. and Motta, P. J. (2005). Analysis of the bite force and mechanical design of the feeding mechanism of the durophagous horn shark Heterodontus francisci. J. Exp. Biol. 208, 3553-3571.

Kane, E. A. and Marshall, C. D. (2009). Comparative feeding kinematics and performance of odontocetes: belugas, Pacific white-sided dolphins and longfinned pilot whales. J. Exp. Biol. 212, 3939-3950.

Kastelein, R. A. and Mosterd, P. (1989). The excavation technique for molluscs of Pacific Walrusses (Odobenus rosmarus divergens) under controlled conditions. Aq. Mamm. 15, 3-5.

Kastelein, R. A., Muller, M. and Terlouw, A. (1994). Oral suction of a Pacific walrus (Odobenus rosmarus divergens) in air and under water. Z. Säugetierkd. 59, 105-115

Kelley, N. P. and Pyenson, N. D. (2015). Evolutionary innovation and ecology in marine tetrapods from the Triassic to the Anthropocene. Science 348, aaa3716.

Kiltie, R. A. (1982). Bite force as a basis for niche differentiation between rain forest peccaries (Tayassu tajacu and T. pecari). Biotropica 14, 188-195.

King, J. E. (1983). Seals of the World, 3rd edn. Ithaca: Cornell University Press.

Kohno, N. and Yanagisawa, Y. (1997). The first record of the Pliocene Gilmore fur seal in the Western North Pacific Ocean. Bull. Nat. Sci. Mus. Tokyo 23 119-130.

Lauder, G. V. (1980). The suction feeding mechanism is sunfishes (Lepomis): an experimental analysis. J. Exp. Biol. 88, 49-72.

Lauder, G. V. (1985). Aquatic feeding in lower vertebrates. In Functional Vertebrate Morphology (ed. M. Hildebrand, D. M. Bramble, K. F. Liem and D. B. Wake), pp. 210-229. Cambridge: Harvard University Press.

Liem, K. F. (1978). Modulatory multiplicity in the functional repertoire of the feeding mechanism in cichlid fishes. I. Piscivores. J. Morphol. 158, 323-360.

Lipps, J. H. and Mitchell, E. (1976). Trophic model for the adaptive radiations and extinctions of pelagic marine mammal. Paleobiology 2, 147-155

Mara, K. R., Motta, P. J. and Huber, D. R. (2010). Bite force and performance in the durophagous bonnethead shark, Sphyrna tiburo. J. Exp. Biol. 313A, 95-105.

Marshall, C. D., Huth, G. D., Edmonds, V. M. Halin, D. L. and Reep, R. L. (1998) Prehensile use of perioral bristles during feeding and associated behaviors of the Florida manatee (Trichechus manatus latirostris). Mar. Mamm. Sci. 14, 274-289.

Marshall, C. D., Maeda, H., Iwata, M., Furuta, M., Asano, S., Rosas, F. and Reep R. L. (2003). Orofacial morphology and feeding behaviour of the dugong, Amazonian, West African and Antillean manatees (Mammalia: Sirenia): functional morphology of the muscular-vibrissal complex. J. Zool. 259, 245-260.
Marshall, C. D., Kovacs, K. M. and Lydersen, C. (2008). Feeding kinematics, suction and hydraulic jetting capabilities in bearded seals (Erignathus barbatus) J. Exp. Biol. 211, 699-708.

Marshall, C. D., Guzman, A., Narazaki, T., Sato, K., Kane, E. A. and SterbaBoatwright, B. (2012). The ontogenetic scaling of bite force and head size in loggerhead sea turtles (Caretta caretta): implications for durophagy in neritic benthic habitats. J. Exp. Biol. 215, 4166-4174.

Marshall, C. D., Marsh, A., Wieskotten, S., Kot, B., Hanke, W., Hanke, F. and Dehndardt, G. (2014a). Feeding kinematics, suction, and hydraulic jetting capabilities in harbor seals (Phoca vitulina). PLOS ONE, 9, e86710.

Marshall, C. D., Wang, J., Rocha-Olivares, A., Godinez-Reyes, C., Fisler, S. Narazaki, T., Sato, K. and Sterba-Boatwright, B. D. (2014b). Scaling of bite performance with head and carapace morphometrics in green turtles (Chelonia mydas). J. Exp. Mar. Biol. Ecol. 451, 91-97.

Mitchell, E. D. (1975). Parallelism and convergence in the evolution of Otariidae and Phocidae. Rapp. P.-V. Réun. - Cons. Int. Explor. Mer. 169, 12-26.

Mori, J., Kubodera, T. and Baba, N. (2001). Squid in the diet of northern fur seals, Callorhinus ursinus, caught in the western and central North Pacific Ocean. Fish. Res. 52, 91-97.

Motani, R., Ji, C., Tomita, T., Kelley, N., Maxwell, E., Jian, D.-Y. and Sanders, P. M. (2013). Absence of suction feeding ichthyosaurs and its implications for Triassic mesopelagic paleoecology. PLoS ONE 8, e66075.

Motta, P. J. (1984). Mechanics and functions of jaw protrusion in teleost fishes: a review. Copeia 1984, 1-18.

Motta, P. J. and Wilga, C. D. (2001). Advances in the study of feeding behaviors, mechanisms, and mechanics of sharks. Environ. Biol. Fish. 60, 131-156.

Nauwelaerts, S., Wilga, C., Sanford, C. and Lauder, G. (2007). Hydrodynamics of prey capture in sharks: effects of substrate. J. R. Soc. Interface 4, 341-345.

Olivier, P. (2015). Foraging ecology of lactating Steller sea lions (Eumetopias jubatus) at Lovushki Island, Russia. Doctoral Dissertation, Texas A\&M University. Osse, J. W. M. and Muller, M. (1980). A model of suction feeding in teleostean fishes with some implications for ventilation. In Environmental Physiology of Fishes (ed. M. A. Ali), pp. 335-352. New York: Plenum Press.

Pauly, D., Trites, A. W., Capuli, E. and Christensen, V. (1998). Diet composition and trophic levels of marine mammals. ICES J. Mar. Sci. 55, 467-481.

Pyenson, N. D., Kelley, N. P. and Parham, J. F. (2014). Marine tetrapod macroevolution: physical and biological drivers on $250 \mathrm{Ma}$ of invasions and evolution in ocean ecosystems. Palaeogeogr. Palaeoclimatol. Palaeoecol. 400 , $1-8$

Reidenberg, J. S. and Laitman, J. T. (1994). Anatomy of the hyoid apparatus in odontoceli (toothed whales): specializations of their skeleton and musculature compared with those of terrestrial mammals. Anat. Rec. 240, 598-624.

Riedman, M. (1990). The Pinnipeds: Seals, Sea Lions, and Walruses Berkeley: University of California Press

Rybczynski, N., Dawson, M. R. and Tedford, R. H. (2009). A semi-aquatic Arctic mammalian carnivore from the Miocene epoch and origin of Pinnipedia. Nature 458, 1021-1024.

Schoener, T. W. (1971). Theory of feeding strategies. Annu. Rev. Ecol. Syst. 2, 369-404.

Sinclair, E. H. and Zeppelin, T. K. (2002). Seasonal and spatial differences in diet in the western stock of Steller sea lions (Eumetopias jubatus). J. Mamm. 83, 973-990.

Sinclair, E. H., Loughlin, T. R. and Pearcy, W. (1994). Prey selection by northern fur seals (Callorhinus ursinus) in the eastern Bering Sea. 92, 144-156.

Thomason, J. J. (1991). Cranial strength in relation to estimated biting forces in some mammals. Can. J. Zool. 69, 2326-2333.

Trites, A. W., Calkins, D. G. and Winship, A. J. (2007). Diets of Steller sea lions (Eumetopias jubatus) in Southeast Alaska from 1993-1999. Fish. Bull. 105, 234-248.

Wainwright, P. C. and Bellwood, D. R. (2002). Ecomorphology of feeding in cora reef fishes. In Coral Reef Fishes: Dynamics and Diversity in a Complex Ecosystem (ed. P. F. Sale), pp. 33-56. Boston: Academic Press.

Wainwright, P. C. and Reilly, S. M. (1994). Ecological Morphology: Integrative Organismal Biology. Chicago: University of Chicago Press.

Wainwright, P. C., McGee, M. D., Longo, S. J. and Hernandez, L. P. (2015) Origins, innovations, and diversification of suction feeding in vertebrates. Integr. Comp. Biol. 55, 134-145.

Werth, A. J. (2000a). Marine mammals. In Feeding: form, Function, and Evolution in Tetrapods (ed. K. Schwenk), pp. 475-514. San Diego: Academic Press.

Werth, A. J. (2000b). A kinematic study of suction feeding and associated behavior in the long-finned pilot whale, Globicephala melas (Traill). Mar. Mamm. Sci. 16 , 299-314.

Werth, A. J. (2007). Adaptations of the cetacean hyolingual apparatus for aquatic feeding and thermoregulation. Anat. Rec. 290, 546-568

Wilga, C. D., Wainwright, P. C. and Motta, P. J. (2000). Evolution of jaw depression mechanics in aquatic vertebrates: insights from Chondrichthyes. Biol. J. Linn Soc. 71, 165-185

Wolf, J. B. W., Tautz, D. and Trillmich, F. (2007). Galapagos and Californian sea lions are separate species: genetic analysis of the genus Zalophus and its implications for conservation management. Front. Zool. 4, 20. 
Wroe, S., McHenry, C. and Thomason, J. J. (2005). Bite club: comparative bite force in big biting mammals and the prediction of predatory behaviour in fossil taxa. Proc. R. Soc. Lond. B Biol. Sci. 272, 619-625.

Wynen, L. P., Goldsworthy, S. D., Insley, S. J., Adams, M., Bickham, J. W., Francis, J., Gallo, J. P., Hoelzel, A. R., Majluf, P., White, R. W. G. et al. (2001). Phylogenetic relationships within the eared seals (Otariidae: Carnivora): implications for the historical biogeography of the Family. Mol. Phylogenet. Evol. 21, 270-284.
Ydesen, K. S., Wisniewska, D. M., Hansen, J. D., Beedholm, K., Johnson, M. and Madsen, P. T. (2014). What a jerk: prey engulfment revealed by high-rate, super-cranial accelerometry on a harbour seal (Phoca vitulina). J. Exp. Biol. 217 2239-2243.

Yonezawa, T., Kohno, N. and Hasegawa, M. (2009). The monophyletic origin of sea lions and fur seals (Carnivora; Otariidae) in the southern hemisphere. Gene 441, 89-99. 